\title{
KORELASI PENGUKURAN TINGKAT KECERAHAN LANGIT DENGAN MENGGUNAKAN KAMERA SMARTPHONE DAN SKY QUALITY METER BERBANTUAN TRACKER
}

\author{
RUSLIN ZAINAL BADDIUN, YUDHIAKTO PRAMUDYA*, OKIMUSTAVA \\ Magister Pendidikan Fisika, FKIP, Universitas Ahmad Dahlan \\ Jl. Pramuka No.42 Pandeyan, Kecamatan Umbulharjo, Kota yogyakarta, Daerah Istimewa \\ Yogyakarta 55161, Telp. 0274-563515 \\ *email : yudhiakto.pramudya@pfis.uad.ac.id
}

\begin{abstract}
Abstrak. Pengukuran kecerahan langit memiliki daya tarik yang sangat besar bagi astronom pemula. Berbagai metode dan cara digunakan dalam menentukan tingkat kecerahan langit. Langit yang gelap dengan benda-benda langit yang jelas terlihat merupakan kondisi langit yang cerah. Penelitian ini dilakukan di Yogyakarta selama 8 malam, pada malam Bulan tidak tampak di ufuk. Pengambilan data dilakukan dengan menggunakan SQM (Sky Quality Meter) dan kamera Smartphone berbantuan Software Tracker. Dalam penelitian ini, penggunaan SQM (Sky Quality Meter) merupakan pembanding dari data yang dihasilkan oleh gambar dari Smartphone yang ekstrak dengan menggunakan Software Tracker. Data kedua alat ukur tersebut berbeda, hal ini dapat dilihat dari perbedaan hasil keluaran data yang dihasilkan, pada SQM (sky Quality Meter) memiliki data keluaran berupa MPSAS (mag/arcsec ${ }^{2}$ ) sedangkan pada Software Tracker, data keluaran berupa luminance $\left(\mathrm{cd} / \mathrm{m}^{2}\right)$. Berdasarkan hasil penelitian menunjukan bahwa kecerahan langit yang ditunjukan berdasarkan data SQM adalah tingkat gelapnya malam, sedangkan pada kamera Smartphone berbantuan Software Tracker menghasilkan nilai Luminance $\left(\mathrm{cd} / \mathrm{m}^{2}\right)$ menunjukan tingkat pencahayaan yang ada pada wilayah yang diamati.
\end{abstract}

Kata kunci: Kecerahan Langit, Luminance, SQM (Sky Quality Meter), Software Tracker, Smartphone

\begin{abstract}
Measurement of the brightness of the sky has a very large attraction, especially for new astronomers. Various methods used to determining the level of brightness of the sky, a dark sky with a variety of stars and other celestial objects that are clearly visible is a clear sky. This research was conducted in Yogyakarta for 8 nights. The nights are moonless night. Data collection was carried out using SQM (Sky Quality Meter) and a Smartphone camera assisted by Software Tracker. In this study, the use of SQM (Sky Quality Meter) is a comparison of the data generated by images from smartphones extracted by using Software Tracker. Data generated from the two measuring devices are different. This can be seen from the difference in the results of the output data generated, the SQM (sky Quality Meter) has output data in the form of mag/arcsec ${ }^{2}$ and in Software Tracker. The output data is in the form of luminance with units of $\mathrm{cd} / \mathrm{m}^{2}$. Based on the results of the study showed that the brightness of the sky shown based on SQM data is the level of darkness of the night, and the data based on the value of luminance $\left(\mathrm{cd} / \mathrm{m}^{2}\right)$ shows the level of light at night on that area.
\end{abstract}

Keywords: Sky Brightness, luminance, SQM (Sky Quality Meter), Software Tracker, Smartphone 


\section{Pendahuluan}

Polusi cahaya merupakan faktor terbesar dalam pengukuran kecerahan langit. Bagi peneliti astronom pemula dalam melakukan pengamatan benda langit, kecerahan langit merupakan dasar utama dalam pengamatan benda langit [1],[2], dalam pengamatan, polusi cahaya menjadi penyebab utama kurangnya kecerahan langit [3], benda-benda langit yang nampak merupakan tanda dari kecerahan langit, dengan kata lain terbebas dari pengaruh luminasi dari cahaya buatan (polusi cahaya) [4],[5].

Pencahayaan buatan manusia, aurora, bulan dan bintang merupakan bagian dari pencahayaan yang menentukan kecerahan langit pada malam hari [6]. Matahari dapat mempengaruhi tingkat kecerahan langit pada malam hari adalah dengan sinarnya yang menjalar melalui atmosfer. Atmosfer memiliki peran lain dalam merefleksikan cahaya, misalnya cahaya buatan hasil dari aktivitas manusia yang dipantulkan atmosfer [7]. Kecerahan langit pada malam hari dengan nilai kelembaban dan suhu bergantung pada waktu, dengan kelembaban memiliki fungsi penting terhadap kecerahan langit malam. Oleh karena itu, perubahan kualitas langit akan seiring dengan perubahan kelembaban [8].

Pengukuran kecerahan langit yang dilakukan oleh peneliti astronomi dilakukan dengan menggunakan peralatan sederhana Sky Quality Meter (SQM). SQM merupakan alat buatan dari UNIHEDRON yang berukuran saku, SQM menunjukan hasil dengan satuan MPSAS (mag/arcsec ${ }^{2}$ ), yang perekamanya dapat dilakukan tiap waktu [9]. Perubahan kegelapan langit pada gerhana Matahari dapat diukur dengan SQM [10].

Belakangan ini peralatan kebutuhan manusia semakin maju, khususnya dalam bidang teknologi, informasi dan komunikasi, seperti Smartphone. Penggunaan Smartphone sangat mudah didapatkan dimanapun, Smartphone memiliki harga yang bervariatif. Penggunanya pula ada di berbagai kalangan. Smartphone memilliki teknologi yang perkembangan di setiap generasinya sangat pesat, khususnya pada teknologi kamera dalam menghasilkan gambar yang berkualitas. Kamera smartphone memiliki dua jenis sensor yaitu CCD (charge Couple Device) dan CMOS (Complementary Metal-oxide Semiconductor). Sensor CCD bekerja dengan cara merubah pixel dan matrix dengan perpindahan register, dan masuk kedalam penyimpanan, sensor pada CMOS memiliki fungsi yang sama yaitu dengan kolom dan baris matrix yang menjadikan pixel akan terstruktur dan efisiensi dalam penyimpanan [11].

Kegunaan kamera smartphone adalah menangkap dan mengabadikan setiap momen yang ada setiap waktunya. Dalam bidang sains, gambar dapat digunakan sebagai bahan pengamatan dari sebuah penelitian. Gambar akan dianalisis dengan diekstrak dari tiap bagian gambarnya dan akan dianalisis dengan berbagai jenis analisis seperti analisis XYZ, HSV, LUV, RGB, Hunter lab, dan CIE [12],[13]. Dalam penelitian ini, gambar yang dihasilkan dengan menggunakan kamera smartphone ini akan diekstrak dan dianalisis dengan menggunakan Software tracker dan Microsoft Excel. Hasil analisis dibandingkan dan dihitung nilai luminance dan kecerahan langit yang tampak pada gambar yang diambil dengan menggunakan kamera Smartphone. 


\section{Metode Penelitian}

Penelitian dilakukan dengan mengukur kecerahan langit dengan menggunakan SQM LU-DL dan Smartphone, dengan kamera Smartphone dan sensor SQM LUDL akan diarahkan ke zenit seperti pada Gambar 1.

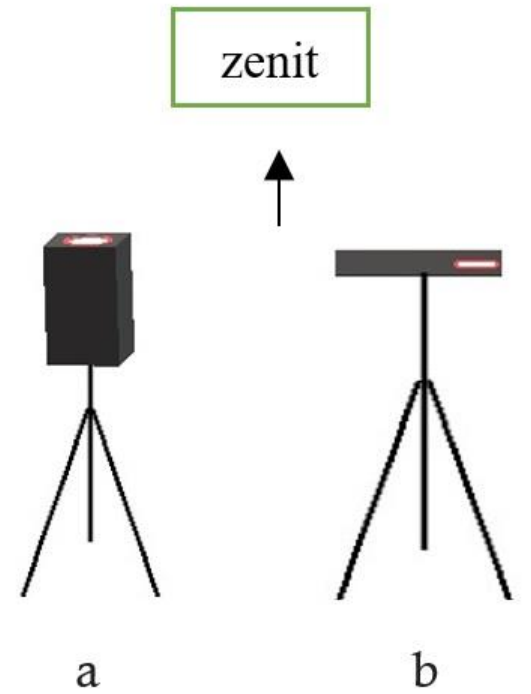

Gambar 1. a. Desain pemasangan alat SQM LU-DL b. Smartphone

Pengamatan dilakukan di wilayah Demangan, Kampung Sapen, D.I. Yogyakarta dengan titik kordinat, $7,78626^{\circ}$ Lintang Selatan dan $110,38673^{\circ}$ Bujur Timur, pada Desember 2018. Tingkat polusi cahaya di wilayah tersebut dapat dilihat seperti pada Gambar 2 [14].

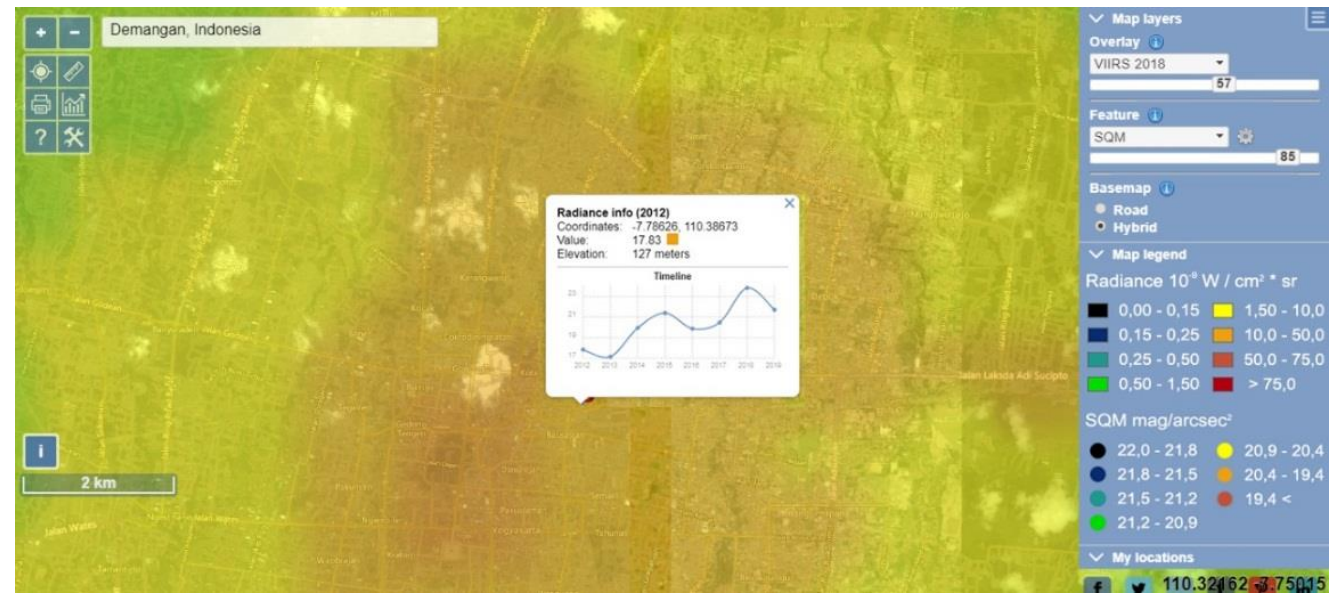

Gambar 2. Light Polution Map (sumber lightpollutionmap.info)

Pengukuran kecerahan menggunakan tipe SQM LU-DL dan menggunakan Smartphone dengan tipe Samsung Galaxy J3-6. Pengukuran dengan menggunakan SQM LU-DL dilakukan dengan bantuan Software Unihedron Device manager (UDM) dan pengukuran dengan menggunakan smartphone yaitu dengan bantuan Software tracker. 
Perekaman data dengan menggunakan SQM LU-DL dilakukan dengan jarak waktu 1 menit untuk setiap data. Data Smartphone diambil dengan jarak waktu 15 menit. Perekaman data dilakukan pada fase Bulan Baru atau pada kondisi bulan tidak berada di ufuk. Perekaman dilakukan pada waktu pengukuran yang memiliki Tingkat Kecerahan Langit (TKL) stabil yaitu pada pukul 10.00 WIB sampai pukul 01.00 WIB.

Data yang didapatkan dari perekaman menggunakan Sky Quality Meter (SQM) berbantuan Software Unihedron Device manager dan kamera Smartphone berbantuan Software Tracker akan dianalisis dengan menggunakan Microsoft Excel. Dalam perekaman data dengan menggunakan kamera Smartphone terlebih dahulu akan diekstrak nilai Red, Green, dan Blue (RGB) dengan menggunakan Software tracker seperti pada Gambar 3.

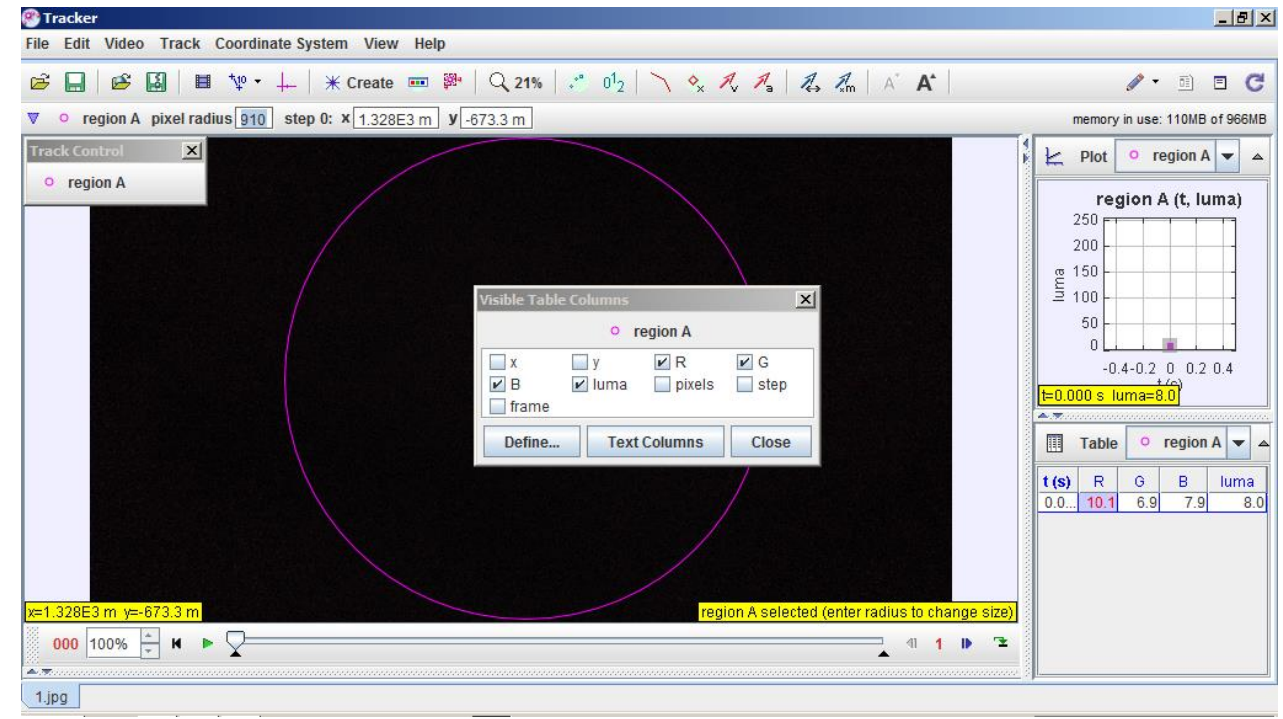

Gambar 3. Mengekstrak nilai RGB dari gambar yang di ambil dengan menggunakan Smartphone

Data RGB yang didapatkan dari gambar yang diekstrak dengan menggunakan Software tracker, selanjutnya akan dianalisis pada microsoft untuk mendapatkan nilai luminance dengan menggunakan persamaan 1 [15].

$$
\mathrm{V}=0,2125 R+0,7154 G+0,0721 B
$$

Luminance RGB (V) dihitung dengan menjumlahkan nilai cahaya merah (R), cahaya hijau (G), dan cahaya biru (B), yang dikalikan dengan kode yang sesuai dari warna tersebut. Data Luminance RGB dari persamaan 1 selanjutnya akan di gunakan untuk menentukan nilai Luminance area gambar dengan menggunakan persamaan 2 [15].

$$
L=\frac{V^{2,4}}{2901,978 E_{v}}
$$


Nilai Luminance gambar (L) dihitung dengan membagi nilai luminance RGB dengan nilai exposure kamera $\left(\mathrm{E}_{\mathrm{v}}\right)$. Nilai eksposur kamera dapat dihitung dengan menggunakan persamaan 3 [15].

$$
E_{v}=\frac{179 \pi}{200} s \frac{T}{f^{2}}
$$

Exposure kamera yang dihitung adalah besar fokus $(f)$ yang digunakan, lamanya waktu rana/aperture dalam menangkap gambar (I), dan besarnya ISO $(s)$ kamera yang digunakan. Nilai Luminance (L) pada persamaan 2 digunakan untuk menentukan konversi kecerahan langit dengan disubsitusikan kedalam persamaan 4 [16].

$$
M=-2,5 \log _{10}\left(9,25 \times 10^{-6} L\right)
$$

\section{Hasil dan Pembahasan}

Pengukuran kecerahan langit dengan menggunakan smartphone, dengan mengekstrak data gambar menggunakan Software tracker dapat dilihat data luminance yang ditampilkan pada Gambar 4.

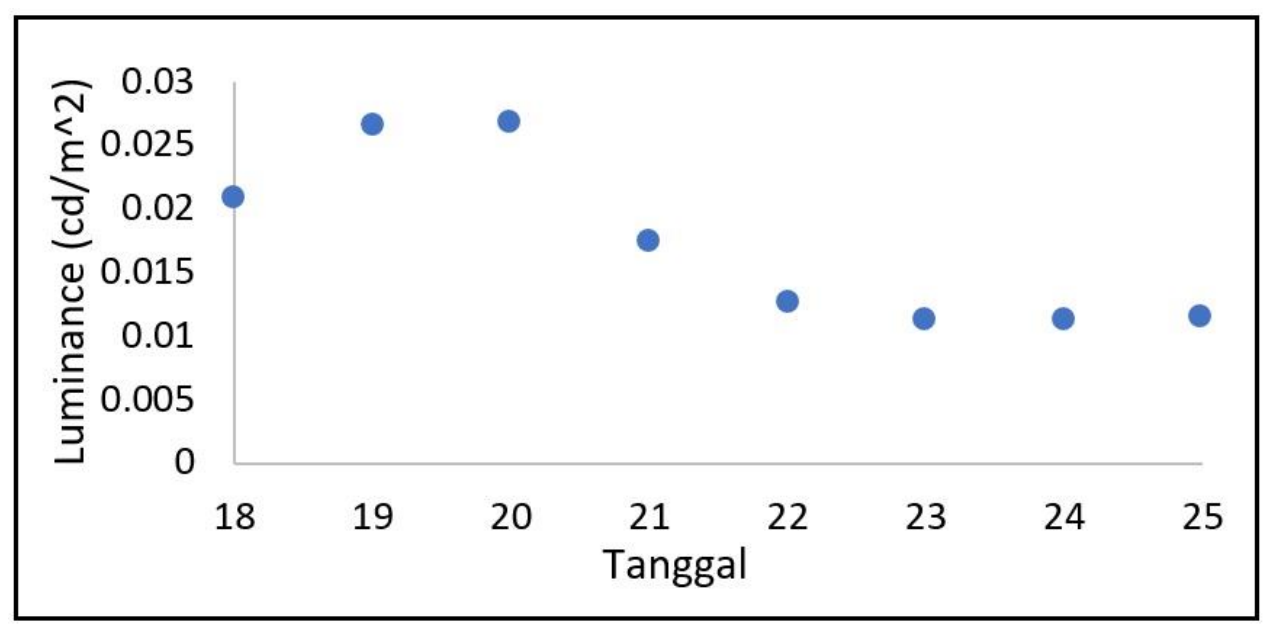

Gambar 4. Nilai Luminance yang di peroleh dari Software Tracker

Berdasarkan pada Gambar 4 dapat dilihat nilai Luminance dari langit berada pada rentan nilai $0,011 \mathrm{Cd} / \mathrm{m}^{2}$ sampai dengan $0,026 \mathrm{Cd} / \mathrm{m}^{2}$, hal ini terjadi akibat pencahayaan yang tidak teratur, pencahayaan yang berlebihan, dan aktivitas transportasi umum yang setiap saat lalu lalang. Tingkat Kecerahan Langit yang diukur dengan menggunakan SQM pada tanggal 18-25 Desember 2018 dapat dilihat pada Gambar 5. Nilai kecerahan langit yang di ukur dengan menggunakan SQM menunjukan rentan nilai dari 16,5 mag/arcsec ${ }^{2}$ sampai dengan yang tertinggi $18,5 \mathrm{mag} / \operatorname{arcsec}^{2}$. Hal ini merupakan salah satu nilai kecerahan langit yang tergolong rendah. Kondisi langit pada rentan nilai tersebut menunjukan kondisi langit yang sedikit berawan dan kondisi langit yang berwarna dikarenakan pantulan dari cahaya yang berasal dari cahaya buatan. 


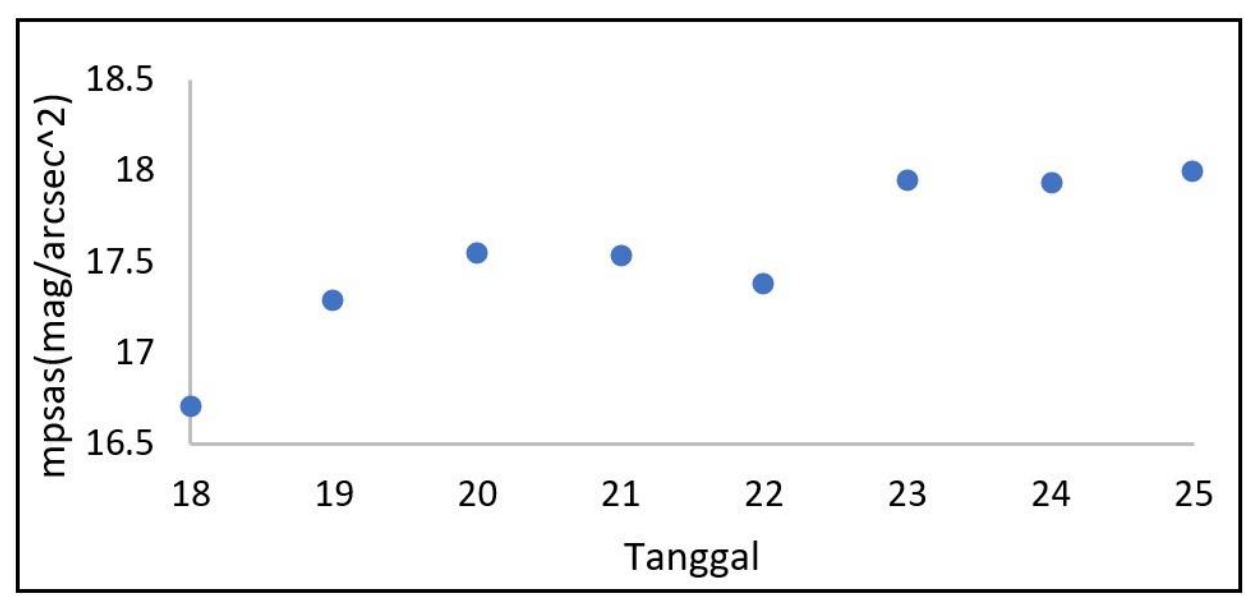

Gambar 5. Nilai kecerahan langit yang di ukur dengan menggunakan SQM (Sky Quality

Meter)

Nilai luminance yang dihasilkan dari perhitungan RGB gambar langit, dilakukan konversi satuan guna untuk melihat kecerahan langit di wilayah tersebut berdasarkan gambar yang diambil menggunakan Smartphone. Untuk dapat melakukan konversi, perlu dilakukan perhitungan konstanta pengkonversian. Persamaan yang mengandung konstanta pengkonversian dapat ditentukan dengan melakukan analisis regresi linear terhadap 2 variabel yaitu nilai luminance oleh kamera Smartphone dan tingkat kecerahan langit yang diukur oleh SQM. Analis regresi linear dapat dilihat pada Gambar 6. Persamaan pengkonversiannya yaitu $y=$ - 61,189 $x+18,117$ dengan nilai $\mathrm{R}^{2}=0,9898$ dengan $x$ adalah nilai luminance dan $y$ adalah tingkat kecerahan langit.

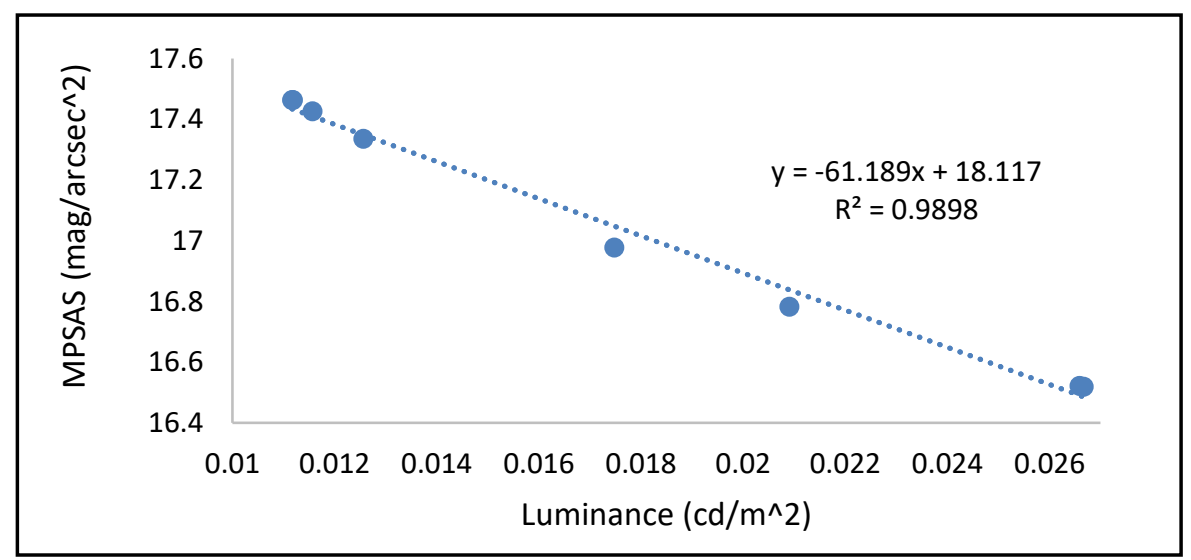

Gambar 6. Grafik hubungan antara MPSAS dan Luminance

Berdasarkan persamaan pengkonversian, nilai luminance dapat diubah ke dalam tingkat kecerahan langit seperti terlihat pada Gambar 7. Kondisi langit yang cerah nilai yang ditunjukan oleh luminance akan kecil sedangkan nilai yang di tunjukan MPSAS akan besar, begitu pula sebaliknya jika langit dalam kondisi tercemar atau 
terkontaminasi (kondisi langit tidak cerah) akan menunjukan nilai MPSAS yang kecil dan sebaliknya nilai luminance yang dihasilkan akan besar.

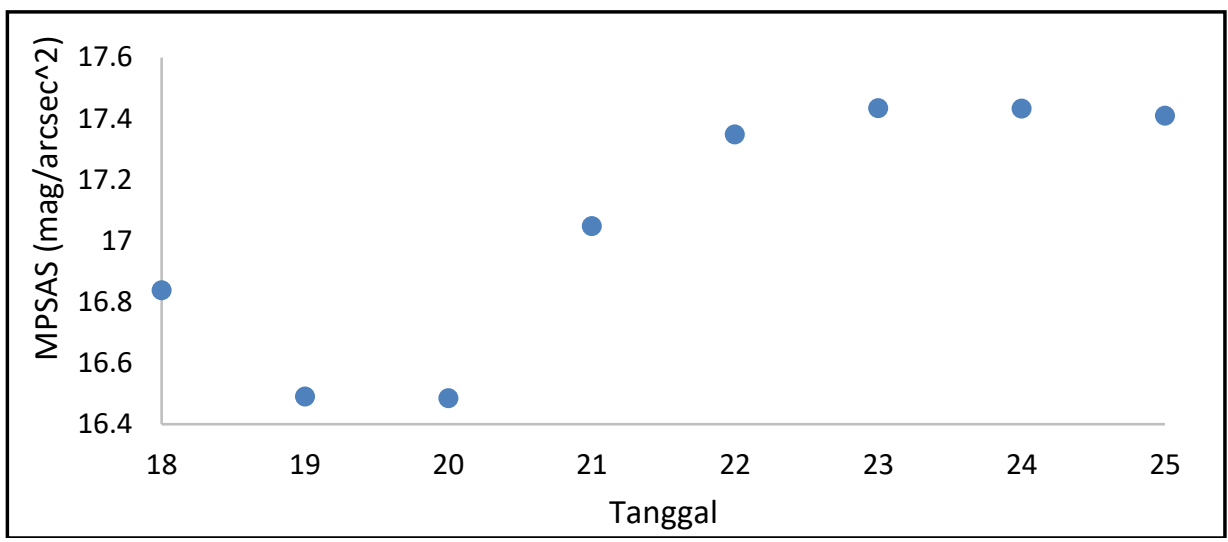

Gambar 7. Kecerahan langit yang di konversi dari nilai luminance

Pengukuran nilai kecerahan langit dengan menggunakan kamera smartphone berbantuan software tracker menunjukkan yang diukur adalah tingkat cahaya yang ditangkap oleh kamera smartphone. Pengukuran kecerahan langit dengan menggunakan SQM menunjukan bahwa semakin gelap langit dan semakin banyak bermunculan bintang maka nilainya akan semakin besar. Kedua metode tersebut berkorelasi linear sehingga mempunyai potensi untuk dapat saling menggantikan. Pola linear antara luminance pada smartphone dan kecerahan langit pada SQM secara statistik memuaskan dengan nilai $\mathrm{R}^{2}$ yang mendekati 1 . Namun, perlu dilakukan pengukuran lanjutan dengan sensor smartphone yang berbeda dan kondisi daerah dengan kecerahan langit yang berbeda untuk dapat diterapkan dengan lebih umum.

Pengukuran kecerahan langit dengan kamera smartphone berdasarkan pengamatan ini menjadi solusi dalam pengukuran tingkat kecerahan langit. Pengukuran kecerahan langit selama pengamatan dengan kamera smartphone memiliki presentase ketepatan dalam pengukuran kecerahan langit sebesar 97,25\%, dengan presentase ralat data sebesar $2,75 \%$. Hasil ini menunjukan tingkat ketepatan smartphone dalam pengukuran kecerahan langit. Keterbatasan kualitas kamera menjadi kendala dalam pengamatan, keakuratan pengaturan eksposur dan kualitas sensor kamera menjadikan presentase keakuratan hasil pengukuran sedikit berbeda dengan alat ukur kecerahan langit. Tetapi kegunaan smarphone dalam pengukuran kecerahan langit dapat menjadi langkah awal bagi para peneliti astronomi pemula dalam polusi cahaya berdasarkan nilai tingkat kecerahan langit. Selain itu, peran masyarakat dapat lebih meningkat dengan berperan sebagai citizen scientist dalam melaporkan kondisi langit di daerah masing-masing.

\section{Kesimpulan}

Kecerahan langit pada malam hari yang di ukur dengan menggunakan smartphone berbantuan Software Tracker menunjukan hasil pengukuran kecerahan langit berdasarkan kualitas pencahayaan yang didapatkan oleh langit (pengukuran polusi cahaya pada langit). Hal ini dapat dilihat dengan merujuk nilai luminance yang 
didapatkan dari perhitungan Red, Green, Blue pada gambar yang ditangkap oleh Smartphone. Nilai kecerahan langit yang dihasilkan dari gambar dan dikonversi ke tingkat kecerahan langit yang diukur dengan SQM menunjukan pola yang linear. Sehingga, metode pengukuran tingkat kecerahan langit dapat juga dilakukan dengan menggunakan kamera Smartphone.

\section{Ucapan Terima Kasih}

Penelitian ini didanai oleh Penelitian Pusat Lembaga Penelitian dan Pengabdian Masyarakat Universitas Ahmad Dahlan tahun 2020. Selain itu, penelitian ini didukung juga oleh Pusat Studi Astronomi dalam hal penggunaan instrumentasi pengukuran.

\section{Daftar Pustaka}

1. F. Holker, C. Wolter, E.K. Perkin, K. Tockner, Light pollution as a biodiversity threat, Trends in Ecology \& Evolution, vol. 25, 2010, hal 681-682.

2. R.G. Stevens, G.C. Brainard, D.E. Blask, S.W. Lockley, M.E. Motta, Adverse health effects of night time lighting: comments on American medical association policy statement, American Journal of Preventive Medicine, vol. 45, 2013, hal 343-346.

3. A. S'anchez de Miguel, M. Aube, J. Zamorano, M. Kocifaj, J. Roby, C. Tapia, Sky Quality Meter measurements in a color changing world, Monthly Notices Royal Astronomical Society, vol 467, 2017, hal. 2966-2979.

4. S. Yao, H.T. Zhang, H.L Yuan, Y.H. Zhao, Y.Q. Dong, Z.R. Bai, L. Deng, Y.J. Lei, Moon night sky brightness simulation for Xinglong station, Research in Astronomy and Astrophysics, Vol. 13, 2013, hal 1

5. M. Aube, Physical behaviour of anthropogenic light propagation into the nocturnal environment, Philosophical Transactions of the Royal Society of London B: Biological Sciences, vol 370, 2015, hal 1-15.

6. P. Cinzano, Night sky photometry with Sky Quality Meter, Istituto di Scienza e Tecnologia dell'Inquinamento Luminoso, vol. 1, 2005, hal 1-13.

7. S.D. Miller, W. Straka, S.P. Mills, C.D. Elvidge, T.F. Lee, J. Solbrig,A. Walther, A.K. Heidenger, S.C. Weiss, Illuminating the Capabilities of the Suomi National Polar-Orbiting Partnership (NPP) Visible Infrared Imaging Radiometer Suite (VIIRS) day/night band, Remote Sensing, vol. 5, 2013, hal 6717-6766.

8. A.Y. Raisal, Y. Pramudya, Okimustava, Muchlas, The moon phases influence on the beginning of astronomical dawn determination in Yogyakarta, International Journal of Science and Applied Science: Conference Series, vol. 2, 2017, hal 4

9. C.C.M. Kyba, T. Ruhtz, J. Fischer, F. H“olker, Lunar skylight polarization signal polluted by urban lighting, Journal of Geophysical Research, vol. 116, 2011, Hal 1-7.

10. Y. Pramudya, M. Arkanuddin, The sky brightness measurement during the 2016 solar eclipse in ternate. Journal of physics: Conference Series, vol. 771, 2016, hal 4

11. S.Z. Nam, Evaluation of University Students' Utilization of Smartphone, International Journal of Smart Home, vol. 7, 2013, hal. 175-182. 
12. K. León, D. Mery, F. Pedreschi, Color measurement in L*a*b* units from RGB digital images. Food Research International, vol. 39, hal 1084-1091.

13. J. Bastie, J.L. Gardner, F. Hengstberger, K.D. Mielenz, J.R. Moore, Y. Ohno, A.C. Parr, A.R. Robertson, G. Sauter, J. Schanda, Photometry - The CIE System of Physical Photometry. International Commission on Illumination, ISO 23539, 2005, hal 1-18.

14. https://www.lightpollutionmap.info, 1 Januari 2020

15. G.G Roy, S. Hayman, W. Julian, Sky Modelling from Digital Imagery, Department Of Architectural and Design Science, Arc Project No. A89530177, 1998, hal 6-11.

16. Unihedron.com, Convert visual mag/arcsecond ${ }^{2}$ to $\mathrm{cd} / \mathrm{m}^{2}$ and convert $\mathrm{cd} / \mathrm{m}^{2}$ to visual mag/arcsecond ${ }^{2}$, http://unihedron.com/projects/darksky/magconv.php, 08 September 2020 